\title{
Kidney volume, kidney function, and ambulatory blood pressure in children born extremely preterm with and without nephrocalcinosis
}

\author{
Alexander Rakow ${ }^{1}$ (D) Åsa Laestadius ${ }^{2} \cdot$ Ulrika Liliemark $^{1} \cdot$ Magnus Backheden $^{3} \cdot$ Lena Legnevall $^{1} \cdot$ Sylvie Kaiser $^{4}$. \\ Mireille Vanpée ${ }^{1}$
}

Received: 5 October 2018 / Revised: 31 May 2019 / Accepted: 11 June 2019 /Published online: 23 July 2019

(C) The Author(s) 2019

\begin{abstract}
Background Reduced kidney volume (KV) following prematurity is a proxy for reduced nephron number and is associated with the development of hypertension and end-stage renal disease in adults. We investigated whether extreme prematurity affects KV, function, and blood pressure in school-aged children and if nephrocalcinosis (NC) developed during the neonatal period had additional effects.

Methods We investigated 60 children at a mean age of 7.7 years: 20 born extremely preterm (EPT <28 weeks gestational age with $\mathrm{NC}(\mathrm{NC}+)), 20$ born EPT without $\mathrm{NC}(\mathrm{NC}-)$, and 19 born as full-term infants (control). We measured KV by ultrasound, collected blood and urine samples to evaluate renal function, and measured office and 24-h ambulatory blood pressure (ABPM). Results Children born EPT had significantly smaller kidneys (EPT (NC+ NC-) vs control (estimated difference, 11.8 (CI - 21.51 to $-2.09 \mathrm{ml}), p=0.018$ ) and lower but normal cystatin $\mathrm{C}$-based glomerular filtration rate compared with control (estimated difference, $-10.11(\mathrm{CI}-0.69$ to -19.5$), p=0.035)$. KV and function were not different between NC+ and NC - groups. Change in $\mathrm{KV}$ in relation to BSA (KV/BSA) from the neonatal period to school age showed significantly more EPT children with neonatal NC having a negative evolution of KV $(p=0.01)$. Blood pressure was normal and not different between the 3 groups. Fifty percent of EPT had a less than $10 \%$ day-to-night decline in ABPM.

Conclusions Kidney growth and volume is affected by EPT birth with NC being a potential aggravating factor. Circadian blood pressure regulation seems abnormal in EPT-born children.
\end{abstract}

Keywords Blood pressure $\cdot$ Circadian regulation $\cdot$ Kidney volume $\cdot$ Nephrocalcinosis $\cdot$ Preterm $\cdot$ Renal function

Abbreviations

ABPM Ambulatory blood pressure measurements

BMI Body mass index

Alexander Rakow

alexander.rakow@ki.se

1 Neonatal Unit, Department of Women's and Children's Health, Karolinska Institutet, Karolinska University Hospital,

17176 Stockholm, Sweden

2 Pediatric Nephrology Unit, Department of Women's and Children's Health, Karolinska Institutet, Karolinska University Hospital, Stockholm, Sweden

3 Unit for Medical Statistics, Karolinska Institutet, Stockholm, Sweden

4 Pediatric Radiology Unit, Department of Women's and Children's Health, Karolinska Institutet, Karolinska University Hospital, Stockholm, Sweden

$\begin{array}{ll}\text { BSA } & \text { Body surface area } \\ \text { EPT } & \text { Preterm } \\ \text { KV } & \text { Kidney volume } \\ \text { NC } & \text { Nephrocalcinosis } \\ \text { NC+ } & \text { Nephrocalcinosis positive } \\ \text { NC- } & \text { Nephrocalcinosis negative }\end{array}$

\section{Introduction}

Extreme prematurity interferes with nephrogenesis, leaving each individual with a finite number of nephrons which might increase the risk for reduced functional capacity and the later development of impaired renal function and hypertension [1-3]. Since Brenner et al. introduced the concept of low nephron number at birth leading to further loss of nephrons by hyperfiltration 
and glomerulosclerosis, multiple studies have described the association between low birth weight and kidney size, kidney function and blood pressure, mostly in adolescents and adults but also in children [1, 4-6]. There is insufficient data to conclude whether prematurity itself is the single adverse event or if additional factors during the neonatal period, such as extra-uterine growth restriction, nephrocalcinosis (NC), nephrotoxic drugs, sepsis, and hypotension, have additional effects on kidney function and the risk for later renal failure, renal hypertension, and overall cardiovascular morbidity and mortality.

$\mathrm{NC}$ is defined as the pathological deposition of calcium crystals in the renal parenchyma. The incidence of neonatal NC varies between 7 and $64 \%$ depending on ultrasonographic criteria and is highest in the most premature infants [7-9]. Ultrasound has been found to be a sensitive and reliable method to detect NC [10]. The etiology of $\mathrm{NC}$ in preterm neonates has not been fully clarified. Furosemide has frequently been implicated as a causative factor due to its hypercalciuric effect [11]. Aminoglycosides, corticosteroids, and xanthenes have also been identified as potential risk factors for NC [12]. Besides nephrotoxic drugs, the preterm infants often experience severe infections, hypotensive crisis, and hypoxia as well as hemodynamic impairment by a persistent ductus arteriosus and/or its treatment, all of which potentially lead to transient or even permanent renal failure [13].

Nutrition is suspected to have an important impact on early postnatal kidney development and health. Recent research suggests that high protein intake, advocated for better growth velocity for extremely preterm (EPT) infants, might have a disadvantageous effect on the kidney. It has been suspected that this high-risk group could have difficulties in metabolizing the amount of protein given, leading to mild metabolic acidosis and possibly to hypercalciuria [14]. Also, the improvements in support of micronutrients to enteral and parenteral feeds including additional calcium, phosphate, and vitamin D bear a potential risk for an imbalance towards stone-promoting factors [15].

The current evidence indicates that neonatal-acquired NC resolves by $50 \%$ during the first year of life and to $75 \%$ by school age without having an impact on kidney function [11, 16]. However, from the few studies focusing on this subject, it can be suspected that $\mathrm{NC}$ has a detrimental effect on the kidneys and therefore cardiovascular health later in life $[9,17]$.

In this study, we investigate whether $\mathrm{NC}$ developed during the neonatal period in children born EPT has an impact on kidney volume and function at school age. Eventual effects on blood pressure are evaluated by 24-h blood pressure monitoring (ABPM).

\section{Subjects and methods}

\section{Subjects}

The study was approved 5by the Ethical Committee at Karolinska University Hospital. Written and oral consent was obtained from all parents and children.

We identified 213 infants born before 28 weeks gestational age (GA) between 2008 and 2011 at the Karolinska University Hospital, Stockholm, Sweden (Fig. 1). Neonatal renal ultrasound was performed in 105 infants, but only 68 had traceable results and images. All neonatal investigations were performed by pediatric radiologists. NC was defined as hyperechogenic reflections in cortex and or medulla visualized in longitudinal and transverse projections. Of the investigated 68 infants, 34 were diagnosed with $\mathrm{NC}(\mathrm{NC}+)$ during their late neonatal period and 34 infants showed no signs of $\mathrm{NC}(\mathrm{NC}-)$. There was no history of hyperoxaluria, cystinuria, or any type of renal tubular acidosis or a history of antenatal or postnatal diagnosis for urogenital malformation in any patient. Twentythree families refused to participate and 4 children died after discharge from the neonatal unit. Twenty children with NC and 21 without $\mathrm{NC}$ during their neonatal period consented to participate in the study. The 172 non-participants (children without ultrasound investigation and children with ultrasound investigation but lost to follow-up or declined to participate or those with incomplete images for review) were not different from the participants with regard to perinatal characteristics. A total of 19 healthy children born at term with appropriate birthweight, without any congenital abnormalities, and with no history of kidney diseases selected from delivery room records were recruited as controls. All children were in good health at the time of the visits.

\section{Follow-up visit}

Clinical data was collected from the neonatal charts with particular attention to factors that could influence renal function, such as nephrotoxic substances: aminoglycosides, vancomycin, loop diuretics, thiazide diuretics, and antenatal and postnatal steroids. GA, birth weight, Apgar scores, intrauterine growth retardation, respiratory distress syndrome (RDS), bronchopulmonary dysplasia (BPD) as defined by NIH, acute kidney injury (AKI) defined and staged by the KDIGO guidelines, patent ductus arteriosus (PDA) requiring treatment, sepsis episodes (clinical and/or culture verified), necrotizing enterocolitis (NEC) Bell stage II or more, surgical interventions for NEC, retinopathy of the premature (ROP) grade III or higher (and or any plus disease), and intraventricular hemorrhage (IVH) or parenchymal hemorrhage as defined by Papile were documented. Small for gestational age (SGA) was defined as a birth weight $<-2$ standard deviations (SD) according to Swedish reference data for normal fetal growth [18]. 
Fig. 1 Flowchart for patient inclusion for extremely preterm infants born $<28$ weeks (w) gestational age (GA) from 2008 to 2011 at Karolinska University Hospital, Stockholm, Sweden, in numbers. US, ultrasound; $\mathrm{NC}+$, screened positive for nephrocalcinosis; $\mathrm{NC}^{-}$, screened negative for nephrocalcinosis

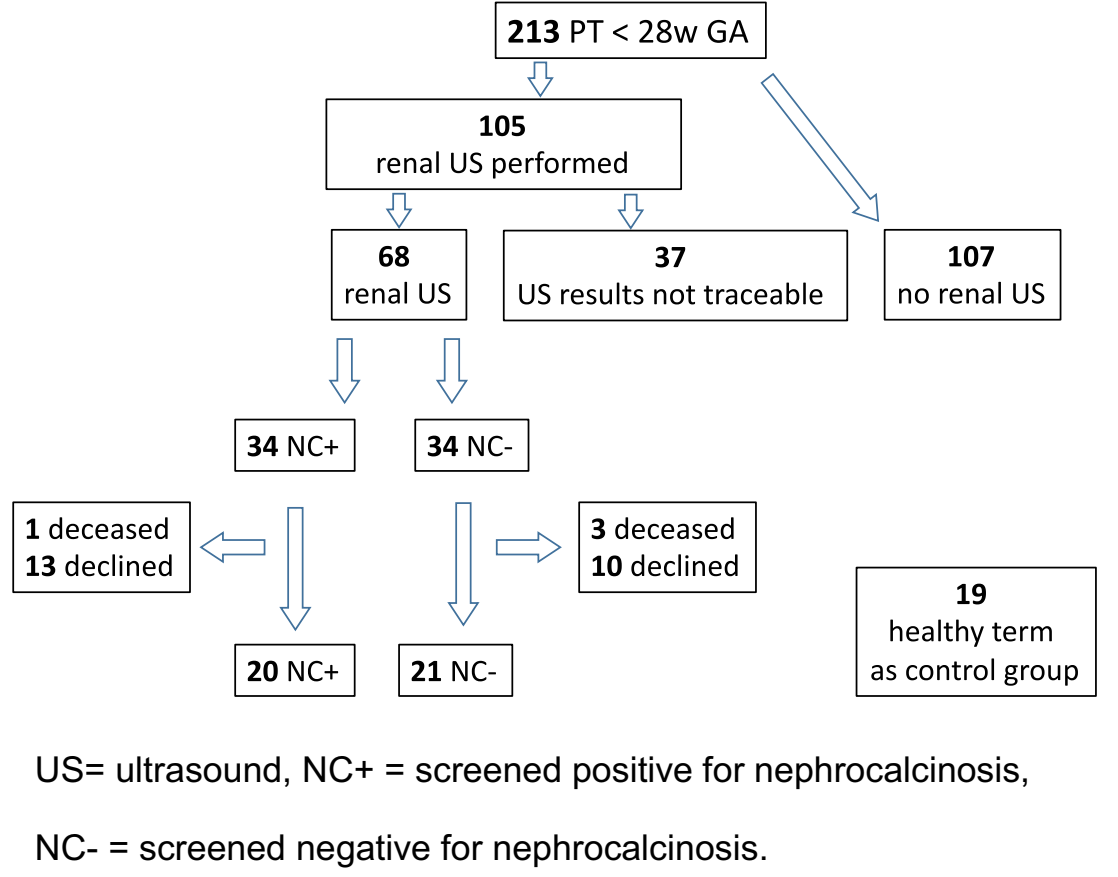

At the visit, patient and parental medical histories, as well as maternal and paternal height and weight, were registered. The same research nurse performed all anthropometric measurements for weight, height, head circumference, and waist circumference on the children, who were wearing light indoor clothing. Height was measured using a wall-mounted stadiometer. Waist circumference was measured midway between the lower rib margin and the iliac crest using a normal measuring tape. Body mass index $\left(\mathrm{kg} / \mathrm{m}^{2}\right)$, body surface area $\left(\mathrm{BSA}=0.007184 \times\right.$ Height $^{0.725} \times$ Weight $\left.^{0.425}\right)$ [19] and waistto-height ratio were calculated.

Office blood pressure was measured in all patients using an automated oscillometric device (GE Healthcare Dinamap Carescape V100). After a 30-min rest, three consecutive measurements were taken on the child's non-dominant arm with an appropriate cuff size (bladder width that was at least $40 \%$ of the arm circumference [20]). We used a SPACELABS 90217A (SpaceLabs Medical Inc., Redmond, Washington, USA) device for ABPM, using the same cuff size as for the office measurements. The device was programmed to register blood pressure every $20 \mathrm{~min}$ between 07:00 AM and 21:00 PM and every $60 \mathrm{~min}$ during the night (21:00 PM07:00 AM). Due to compliance difficulties in 21 children $(12 / 20 \mathrm{NC}+, 9 / 20 \mathrm{NC}-)$ with neuropsychiatric disorder (ADHD, autism, and autism spectrum), we accepted $>50 \%$ of successful readings instead of the standard $>75 \%$ for statistical analysis [21]. The rest periods were described by the patient's parents, and day and night measurements were adjusted accordingly. The non-dipper pattern was defined as nocturnal $\mathrm{BP}_{\text {Systolic }}$ or $\mathrm{BP}_{\text {Diastolic }}<10 \%$ relative to the diurnal mean value [22]. Hypertension was defined as $>95$ th percentile according to gender and length. BP > 90th but $<$ 95th percentile was defined as high normal BP [22].

\section{Renal function estimation}

Morning urine samples were collected from all study participants and analyzed for sodium, potassium, creatinine, albumin, calcium, phosphate, magnesium and protein $\mathrm{HC}(\alpha-1-$ microglobulin) and immunoglobulin G. Sodium and potassium were measured using potentiometry with ion-selective electrodes (Cobas 8000, Cobas C ISE2, Roche, Basel Switzerland). Urine phosphate, calcium, and magnesium were measured using photometric technique (Cobas 8000 Cobas CC 701 Roche, Basel Switzerland), and urine albumin was measured using immunochemical and turbodimetric method (Cobas 8000 Cobas CC 701 Roche, Basel Switzerland). Protein HC and immunoglobulin G were measured by immunochemical and nephelometric method (BN Pro Spec, Siemens Healthcare, Erlangen, Germany).

Blood samples were taken in 55 patients $(\mathrm{NC}+, 17$; $\mathrm{NC}-$, 21 ; control, 17) after placing a local application of a topical anesthetic cream containing $2.5 \%$ lidocaine and $2.5 \%$ prilocaine (EMLA; Astra Zeneca, Sodertalje, Sweden). Blood samples were investigated for plasma sodium and potassium using potentiometry with ion-selective electrodes (Cobas 8000, Cobas C ISE2, Roche, Basel Switzerland); calcium, phosphate, alkaline phosphatase, creatinine, and urea using photometric technique; and cystatin $\mathrm{C}$ using immunochemical and turbidometric method (Cobas 8000 Cobas CC 701 Roche, Basel Switzerland). For the estimation of GFR, 
we used the simplified Schwartz formula (with $k=36$ ) as well as the cystatin C-based CAPA formula [23, 24].

\section{Assessment of renal volume}

Ultrasound of the kidneys during the neonatal period (20082011) was performed by pediatric radiologists using a Siemens S 2000 with a 6C2 curved transducer (Siemens, Erlangen, Germany) at an average age of 36 weeks postmenstrual age following local guidelines. All images from the neonatal period for the 41 included children were reviewed by a senior pediatric radiologist in 2018. Diagnosis of NC was confirmed in 39 of the 41 cases. In each group ( $\mathrm{NC}+\mathrm{NC}-$ ), one patient was misdiagnosed and moved to the opposite group. Kidney volume for the neonatal period was calculated in 36 out of the 41 patients using the equation for an ellipsoid described elsewhere [25] and expressed as a ratio to BSA (KV/BSA) [26]. In the remaining 5 patients, the reviewed images were incomplete and volume calculation therefore was not possible.

Ultrasound of the kidneys at school age visits was performed by a single experienced user. All investigations were performed with a Philips EPIQ 7G with SW1.5.2 software (Philips Ultrasound, Inc. 22100 Bothell Everett Hwy Bothell, WA 98021-8431, USA) using a C9-2 curved transducer. Multiple (at least two) measurements of kidney length, width, and depth were performed. An average of these measurements was entered in the equation for an ellipsoid, and $\mathrm{KV}$ was calculated [25]. Results from volumetric kidney measurements were adjusted for BSA by using linear regression analysis but also by using the ratio of kidney volume (KV) to BSA [26]. Predicted KV was calculated for each individual using the equation described by Dinkel et al. [25].

\section{Statistics}

For descriptive statistics, continuous variables were presented with mean and standard deviation (SD). Continuous variables, approximately normally distributed, were analyzed with respect to the three defined groups, using analysis of variance (ANOVA). In order to adjust for continuous prognostic variables, covariance analysis was used (ANCOVA). Stepwise regression analysis was used to examine the impact of a set of prognostic variables. The coefficient of determination, $\mathrm{R}^{2}$ was used to compare the precision of different models. Nonnormal continuous variables were analyzed with KruskalWallis test. Dichotomous variables were analyzed with cross tables and Pearson's chi-square test. As additional analyses, the kidney volume was analyzed with a mixed effects model including right and left volume in the same analysis. A hierarchical model with the child as the main unit was set up, taking into consideration the correlation between right and left side, with the covariance structure unstructured (UN). In all statistical analyses, the relevant assumptions were checked. The significance level alpha was set to 0.05 .

\section{Results}

\section{Subject characteristics}

The neonatal characteristics and morbidities did not differ significantly between the $\mathrm{NC}+$ and $\mathrm{NC}-$ groups; however, the $\mathrm{NC}+$ group tended to be younger, smaller, and with more vancomycin, less prenatal steroid use, and more frequent IVH for all grades (Table 1). Children in the control group at visit were insignificantly older but significantly heavier, taller, and had larger head circumference, BSA, and LBM, but lower waist-to-height ratio. Between $\mathrm{NC}+$ and $\mathrm{NC}-$, only SDS for height and waist-to-height ratio were different at visit (Table 2). None of the kidney ultrasound investigations showed signs of persistent NC. One child from the control group was referred for follow-up ultrasound because of mild unilateral pelvic dilatation (excluded).

\section{Kidney volume}

Unadjusted total kidney volumes (KV) were significantly lower for both preterm groups in comparison with controls $(\mathrm{NC}+=90.1 \mathrm{ml}, \mathrm{NC}-=93.8 \mathrm{ml}$, control $=118.4 \mathrm{ml}$, $p=0.0004$, ANOVA, Fig. 2). After adjusting KV for $\mathrm{BSA}$, the analysis was no longer significant between $\mathrm{NC}+$ and controls $(p=0.056)$ (Table 3$)$. The mixed effects model analysis where BSA, gender, and each kidney side were included showed a significantly lower right and left $\mathrm{KV}$ for girls in the $\mathrm{NC}+$ group compared with girls in the control group $(p=0.016)$. The effects of the following factors on total $\mathrm{KV}$ by using stepwise linear regression were also tested: age at visit, AKI, PDA, NEC, BPD, sepsis, and treatment with furosemide (days) and antenatal steroids. None of the tested confounding factors seemed to have the potential to explain a difference in total $\mathrm{KV}$ between the two preterm groups. Total KV calculated as the ratio of $\mathrm{KV}$ and BSA (KV/BSA) [26] was significantly lower for the $\mathrm{NC}+$ group of preterm-born children compared with controls $(p=0.016)$, but not reaching significance for the NC- group ( $p=0.08)$ (Table 4, Fig. 2). Both preterm groups taken together had significantly lower kidney volume in comparison with controls (Table 4). There was no significant difference between $\mathrm{NC}+$ and $\mathrm{NC}-$ groups. Regardless of the method of the statistical analysis, there were differences in kidney volume between boys and girls (Fig. 3) as well as laterality of the kidney shown in Tables 3 and 4. Total KV calculated as a ratio to BSA (KV/BSA) for the neonatal period was not significantly different between infants with or without $\mathrm{NC}(\mathrm{NC}+$ : 
Table 1 Neonatal characteristics and morbidities for the three groups: Extremely preterm infants born $<28$ weeks gestational age (EPT) with nephrocalcinosis $(\mathrm{NC}+)$ or without nephrocalcinosis $(\mathrm{NC}-)$ during the neonatal period and full-term controls. Values are presented as means and standard deviations (SD) or numbers or percent $(n(\%))$ as specified

\begin{tabular}{|c|c|c|c|c|}
\hline & $\begin{array}{l}\mathrm{EPT}+\mathrm{NC} \\
n=20\end{array}$ & $\begin{array}{l}\mathrm{EPT}-\mathrm{NC} \\
n=21\end{array}$ & $\begin{array}{l}\text { Control } \\
n=19\end{array}$ & $p$ value \\
\hline Males, $n(\%)$ & $9(45 \%)$ & $13(62 \%)$ & $10(53 \%)$ & $0.55 / 0.27$ \\
\hline Gestational age, weeks & $25.5(1.2)^{*}$ & $25.9(1.3)^{*}$ & $39.7(1.6)$ & $<0.0001 / 0.22$ \\
\hline Birth weight, $g$ & $755(124)^{*}$ & $841(202)^{*}$ & $3586(477)$ & $<0.0001 / 0.10$ \\
\hline Birth weight, SDS & $-0.93(0.78)^{*}$ & $-0.87(1.22)^{*}$ & $0.19(0.93)$ & $0.0012 / 0.85$ \\
\hline Birth length, cm & $32.4(1.8)^{*}$ & $33.6(2.6)^{*}$ & $50.4(1.9)$ & $<0.0001 / 0.08$ \\
\hline Head circumference, $\mathrm{cm}$ & $23.3(1.3)^{*}$ & $24.0(1.8)^{*}$ & $34.6(1.4)$ & $<0.0001 / 0.12$ \\
\hline Small for gestational age, $n(\%)$ & $3(15 \%)^{*}$ & $5(24 \%)^{*}$ & $0(0)$ & $0.028 / 0.47$ \\
\hline Apgar score at $5 \mathrm{~min}$ & $6.7(2.9)^{*}$ & $7.4(2.1)^{*}$ & $10(0.0)$ & $0.0007 / 0.36$ \\
\hline Apgar score at $10 \mathrm{~min}$ & $8.4(1.7)^{*}$ & $8.7(1.9)^{*}$ & $10(0.0)$ & $0.022 / 0.59$ \\
\hline $\mathrm{BPD}, n(\%)$ & $12 / 20(60 \%)$ & $10 / 21(48 \%)$ & - & 0.42 \\
\hline PDA (treated + untreated), $n(\%)$ & $17 / 20(85 \%)$ & $17 / 21(83 \%)$ & - & 0.7 \\
\hline PDA, medically treated, $n(\%)$ & $10 / 17(59 \%)$ & $13 / 17(68 \%)$ & - & 0.2 \\
\hline PDA, surgically treated, $n(\%)$ & $9 / 17(53 \%)$ & $8 / 17(47 \%)$ & - & 0.7 \\
\hline ROP (stage III or $>$ ), $n(\%)$ & $3 / 20(15 \%)$ & $2 / 21(9.5 \%)$ & - & 0.6 \\
\hline NEC (stage II or $>$ ), $n(\%)$ & $11 / 20(55 \%)$ & $11 / 21(54 \%)$ & - & 0.8 \\
\hline NEC, surgically treated, $n(\%)$ & $3 / 11(27 \%)$ & $4 / 11(32 \%)$ & - & 0.6 \\
\hline Sepsis, $n(\%)$ & $11 / 20(55 \%)$ & $14 / 21(61 \%)$ & - & 0.4 \\
\hline IVH (I-II), $n(\%)$ & $10 / 20(50 \%)$ & $6 / 21(29 \%)$ & - & 0.15 \\
\hline IVH (III-IV), $n(\%)$ & $4 / 20(20 \%)$ & $1 / 21(5 \%)$ & - & 0.13 \\
\hline AKI (all stages), $n(\%)$ & $8 / 20(40 \%)$ & $12 / 21(57 \%)$ & - & 0.3 \\
\hline Duration of aminoglycosides, days & $17.1(6.4)$ & $16.2(11.2)$ & - & 0.8 \\
\hline Vancomycin treatment, $n(\%)$ & $18 / 20(90 \%)$ & $15 / 21(71 \%)$ & - & 0.1 \\
\hline Duration of vancomycin, days & $16(9)$ & $22(11)$ & - & 0.14 \\
\hline Furosemide treatment (iv/po), $n(\%)$ & $18 / 20(90 \%)$ & $19 / 21(91 \%)$ & - & 0.95 \\
\hline Duration of all furosemide, days & $38(32)$ & $49(56)$ & - & 0.49 \\
\hline NSAID for PDA closure, $n(\%)$ & $10 / 20(50 \%)$ & $13 / 21(62 \%)$ & - & \\
\hline $\begin{array}{l}\text { Antenatal steroids: full course, } n(\%) \\
\text { Incomplete course }\end{array}$ & $\begin{array}{l}11 / 20(55 \%) \\
7 / 20(35 \%)\end{array}$ & $\begin{array}{l}17 / 21(81 \%) \\
2 / 21(10 \%)\end{array}$ & - & 0.11 \\
\hline Postnatal inhaled steroids, $n(\%)$ & $13 / 20(65 \%)$ & $15 / 21(71 \%)$ & - & 0.65 \\
\hline Postnatal systemic steroids, $n(\%)$ & $4 / 20(20 \%)$ & $3 / 21(14 \%)$ & - & 0.62 \\
\hline All postnatal steroids, days & $3(24)$ & $43(50)$ & - & 0.44 \\
\hline
\end{tabular}

Statistics were done with one-way ANOVA for comparison of all three groups/and with Pearson's chi-square test for NC+ versus NC-. Asterisk is indicating $p$ values $<0.05$ and considered significant. $S D S$ standard deviation score, $B P D$ bronchopulmonary dysplasia, $P D A$ persistent ductus arteriosus, $R O P$ retinopathy of the premature, $N E C$ necrotizing enterocolitis, $I V H$ intraventricular hemorrhage, $A K I$ acute kidney injury, $N S A I D$ nonsteroidal anti-inflammatory drugs

$131.4 \mathrm{ml}(\mathrm{SD} 21.1) ; \mathrm{NC}-109.9 \mathrm{ml}(\mathrm{SD} 29.7), p=0.07$ using non-parametric Kruskal-Wallis test). The KV/BSA ratio from the neonatal period compared with the measurements at school age showed that children who had suffered from $\mathrm{NC}(\mathrm{NC}+)$ during the neonatal period had significantly lower $\mathrm{KV} / \mathrm{BSA}$ ratios than those without $\mathrm{NC}$ $(\mathrm{NC}-)(\mathrm{NC}+81.05, \mathrm{NC}-103.4 ; p=0.0036)$. Among $\mathrm{NC}+$ children, only 2 of $18(11 \%)$ had a rise in KV/BSA ratio from neonatal to school age, while 9 of $18(50 \%)$ in the $\mathrm{NC}-$ group showed a rise in $\mathrm{KV} / \mathrm{BSA}$ ratio $(p=0.01)$.

\section{Kidney function}

All groups had normal estimated glomerular filtration rate (eGFR) calculated by the cystatin $\mathrm{C}$-based CAPA formula but showed lower values for the $\mathrm{NC}-$ group compared with controls as well as for both preterm groups taken together $(\mathrm{NC}+120, \mathrm{NC}-113$, control $126.3 \mathrm{ml} / \mathrm{min} / 1.73 \mathrm{~m}^{2}, p=0.012,0.035$ respectively). The difference between the $\mathrm{NC}+$ and $\mathrm{NC}-$ groups was not significant $(p=0.11)$. 
Table 2 Characteristics at follow-up visit for the three groups: Extremely preterm infants born $<28$ weeks gestational age (EPT) with nephrocalcinosis $(\mathrm{NC}+)$ or without nephrocalcinosis $(\mathrm{NC}-)$ during the neonatal period and full-term controls. Values are presented as means and standard deviation (SD)

\begin{tabular}{|c|c|c|c|c|}
\hline & $\begin{array}{l}\text { EPT NC+ } \\
n=20\end{array}$ & $\begin{array}{l}\text { EPT NC- } \\
n=21\end{array}$ & $\begin{array}{l}\text { Control } \\
n=19\end{array}$ & $\begin{array}{l}p \text { value } \\
\text { ANOVA/NC+ vs NC- }\end{array}$ \\
\hline Age at visit, years & $7.8(1.0)$ & $7.4(1.1)$ & $8.1(1.2)$ & $0.1 / 0.2$ \\
\hline Body weight, $\mathrm{kg}$ & $22.5(5.8)^{*}$ & $22.3(5.4)^{*}$ & $26.7(4.0)$ & $0.02 / 0.9$ \\
\hline Body weight SDS & $-1.26(1.5)^{*}$ & $-0.87(1.3)^{*}$ & $-0.02(0.7)$ & $0.01 / 0.4$ \\
\hline Body height, $\mathrm{cm}$ & $120(7.6)^{*}$ & $121(8.3)^{*}$ & $129(8.6)$ & $0.0005 / 0.5$ \\
\hline Body height SDS & $-1.2(1.2)^{*}$ & $-0.5(0.9)^{* \#}$ & $0.2(0.7)$ & $0.0001 / 0.03$ \\
\hline Head circumference, $\mathrm{cm}$ & $51.1(1.6)^{*}$ & $51.8(2.2)^{*}$ & $53.4(1.6)$ & $0.0009 / 0.2$ \\
\hline Waist circumference, $\mathrm{cm}$ & $58.0(7.4)$ & $55.5(5.5)$ & $57.7(3.3)$ & $0.3 / 0.2$ \\
\hline Waist-to-height ratio & $0.48(0.05)^{*}$ & $0.45(0.03)^{\#}$ & $0.44(0.02)$ & $0.005 / 0.04$ \\
\hline Body mass index & $15.5(2.4)$ & $14.9(1.8)$ & $15.7(1.2)$ & $0.4 / 0.4$ \\
\hline Body mass index SDS & $-0.7(1.4)$ & $-0.9(1.6)$ & $-0.2(0.8)$ & $0.3 / 0.6$ \\
\hline Body surface area & $0.86(0.13)^{*}$ & $0.86(0.12)^{*}$ & $0.98(0.11)$ & $0.003 / 0.9$ \\
\hline Lean body mass $(n=12 / 16 / 17)$ & $15.8(2.7)^{*}$ & $15.6(3.0)^{*}$ & $19.6(3.5)$ & $0.001 / 0.8$ \\
\hline
\end{tabular}

*Significant difference between the three groups using one-way ANOVA ( $p$ values $<0.05$ ). ${ }^{\#}$ Significant differences $(p$ values $<0.05)$ between NC+ and $\mathrm{NC}-$ born children using Pearson's chi-square test

There was no difference between the groups when using the simplified Schwartz formula (eGFRcreatinine with $k=36$ ) $\left(\mathrm{NC}+114.4, \mathrm{NC}-112.5\right.$, control $104.6 \mathrm{ml} / \mathrm{min} / 1.73 \mathrm{~m}^{2}, p=$ $0.3)$. Although entirely normal, plasma creatinine was significantly higher in controls compared with both groups of preterm-born children (NC+ 38.5 (5.9); $\mathrm{NC}-40.1$ (7.9); control $46.2 \mu \mathrm{mol} / 1(8.6), p=0.011)$. Urinary proteins and electrolytes were not significantly different between the three groups (data on request).

\section{Blood pressure}

Office blood pressure and systolic and diastolic standard deviation score (SDS) were not different between the three groups (mean (SD); NC+, 0.18 (0.94); NC-, - 0.07 (0.72); control, $-0.005(0.72), p=0.58)$. Four of the preterm-born children had high office blood pressure measurements: 3 had both systolic and diastolic, and 1 had isolated diastolic blood pressure above the 90th percentile. One child in the control group had isolated high diastolic blood pressure measurements above the 90th percentile.

ABPM readings were successful in 34 of the 41 EPT-born children. Neurodevelopmental disorders of autism spectrum disorders and/or ADHD were present in 16 children born EPT $(12 / 20 \mathrm{NC}+(60 \%) ; 4$ of $21 \mathrm{NC}-(19 \%))$. In seven of these children, ABPM measurements were not possible due to compliance problems or had to be discarded because of low quality. However, none of the investigated children with ADHD or autism spectrum diseases was on medical treatment at the time of investigation. The results of ABPM in the 34 performed were in the normal range for all preterm-born children. ABPM could verify the high office blood pressure measurements in only one of the five patients mentioned above. The majority of the children had systolic values below or at the 50th percentile (Table 5). There was no difference between $\mathrm{NC}+$ and $\mathrm{NC}-$ with regard to the distribution among the percentiles. Seventeen of 34 preterm-born children $(50 \%)$ $(\mathrm{NC}+9 ; \mathrm{NC}-8)$ had a day-to-night decline (night dipping) of $<10 \%$ (Table 5).

\section{Discussion}

After adjusting KV for BSA, we can show that extremely preterm-born children already at early school age have significantly smaller kidneys than their peers born at term. We cannot prove that $\mathrm{NC}$ has a clear effect on those findings, but we can show that mainly preterm-born children exposed to $\mathrm{NC}$ are the ones with smaller kidneys in comparison with controls. We were also able to show that the evolution of the KV/BSA ratio from the neonatal period to school age seems to be negatively affected for those who suffered from $\mathrm{NC}$ during their neonatal period. It remains speculative whether $\mathrm{NC}$ during the neonatal period has an adverse effect on kidney growth. We fully appreciate that the number of patients included does not allow any causative relation. However, we regard this observation as important and interesting.

Kidney function and office blood pressure and ABPM were normal and not different between the groups. However circadian blood pressure regulation seemed to be significantly altered in both groups of preterm-born children.

With regard to NC, Giapros et al. followed children born under 32 weeks GA to the age of 24 months and demonstrated that those born preterm who had developed NC had shorter 
Fig. 2 Total kidney volume presented as a ratio to body surface area (KV/BSA) for the three groups. Children born preterm screened positive for nephrocalcinosis $(\mathrm{NC}+)$, screened negative for nephrocalcinosis (NC-), and healthy term controls without nephrocalcinosis. * Significant difference between $\mathrm{NC}+$ and controls $(p$ values $<$ $0.05)$. Results from the ANCOVA analysis models and planned comparisons.

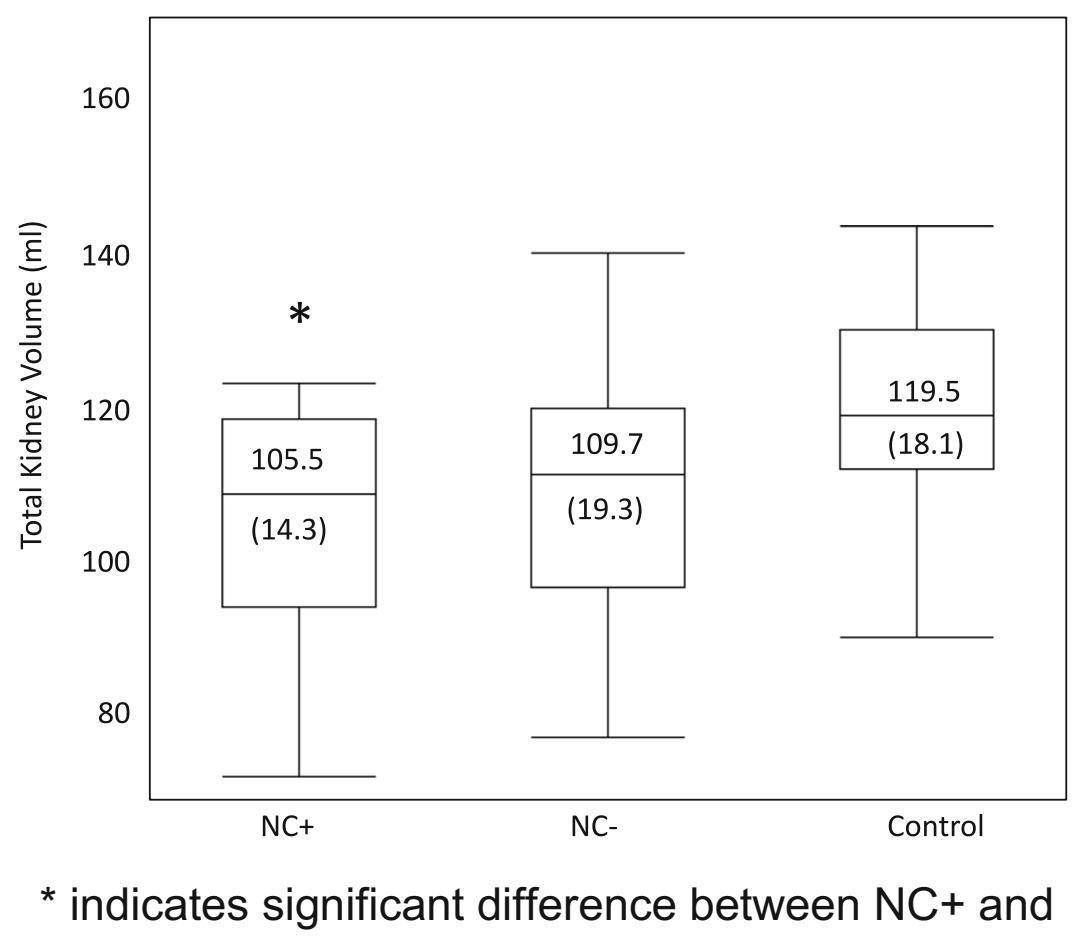

Controls ( $P$ values $<0.05)$. Results from the ANCOVA right-sided kidney length [9]. Kist-van Holthe et al. found smaller kidneys in preterm-born children at the age of 7.5 years but no effect of NC on kidney volume.

The association between prematurity and smaller kidneys in infants and toddlers up to childhood has been shown in a number of follow-up studies [27, 28]. Other long-term followup studies, including our own previous research, showed somewhat conflicting results [29]. Kwinta and later Stazec et al. could confirm reduced kidney volume measured by ultrasound in very low birth weight (VLBW) children at the age of 7 and 11 years [30,31]. A study on renal biopsy material in 31 children with focal segmental glomerulosclerosis (FSGS) or minimal change nephrotic syndrome (MCNS) at a mean age of 11 years, where 8 children also were born very preterm (mean: 25.4 GA), showed significantly lower glomerular density and greater glomerular volume in the children born preterm compared with those with normal birth weight [32]. The vicious circle of fewer nephrons in children born with low birth weight introduced by Brenner et al. might be particularly important in patients where there already exists severe renal pathology [33].

Our findings also show that school-aged girls born EPT have smaller kidneys than controls - a finding not present for boys. Keijzer-Veen et al. also found preterm born females to be more affected than males at young adulthood [34].
Kidney function was, by definition, normal among all three groups. Cystatin C-based eGFR, which has been advocated to be more appropriate for the age group investigated here, was lower in the group of children born prematurely in comparison with the control group $(p=0.036)$ [35]. Using the modified Schwartz formula to establish eGFR, four children in the preterm groups and one child from the control group had eGFR below $85 \mathrm{ml} / \mathrm{min} / 1.73 \mathrm{~m}^{2}$, which can be defined as mild renal insufficiency [36]. Serum creatinine levels were higher in the control group which might be explained by the higher muscle mass in that group. We could not detect any difference between preterm-born children with or without $\mathrm{NC}$ in regard to eGFR. This is in slight contrast to the findings in the study by Kist-van Holthe et al. who showed a higher number of children in their $\mathrm{NC}+$ group with mild chronic renal insufficiency, but these results were not significantly different to the children born preterm without NC [17]. Giapros et al. could not detect an effect on GFR in his follow-up study focusing on children born preterm up to 24 months of age [9]. Follow-up studies of the same cohort at the age of 15,20 , and 30 years of age will be informative and necessary to answer the abovementioned statements.

Early elevated blood pressure in children born very preterm, and even hypertension, has been reported in previous studies $[37,38]$. It is debatable whether office blood pressure 
Table 3 Statistical results for kidney volume adjusted for BSA comparing the different groups: extremely preterm infants born $<28$ weeks gestational age with nephrocalcinosis $(\mathrm{NC}+)$ or without nephrocalcinosis during the neonatal period $(\mathrm{NC}-)$ and full-term controls

\begin{tabular}{|c|c|c|}
\hline Kidney volume adjusted for BSA at visit & $\begin{array}{l}\text { Estimated difference } \\
\text { (CI 95\%) }\end{array}$ & $p$ \\
\hline \multicolumn{3}{|l|}{ Total kidney volume } \\
\hline $\mathrm{NC}+$ vs NC- & $-2.97(-13.09+7.14)$ & 0.55 \\
\hline $\mathrm{NC}+$ vs control & $-11.12(-22.57+0.31)$ & 0.056 \\
\hline $\mathrm{NC}-$ vs control & $-8.15(-19.4+3.06)$ & 0.15 \\
\hline$(\mathrm{NC}+\mathrm{NC}-)$ vs control & $-9.64(-19.79+0.51)$ & 0.062 \\
\hline \multicolumn{3}{|l|}{ Right kidney volume } \\
\hline $\mathrm{NC}+$ vs NC- & $-4.72(-10.310 .86)$ & 0.09 \\
\hline $\mathrm{NC}+$ vs control & $-8.7(-14.9-2.5)$ & $0.0068^{*}$ \\
\hline $\mathrm{NC}-$ vs control & $-3.97(-10.092 .13)$ & 0.19 \\
\hline$(\mathrm{NC}+\mathrm{NC}-)$ vs control & $-6.34(-11.83-0.85)$ & $0.024 *$ \\
\hline \multicolumn{3}{|l|}{ Left kidney volume } \\
\hline $\mathrm{NC}+$ vs NC- & $2.23(-5.259 .72)$ & 0.55 \\
\hline $\mathrm{NC}+$ vs control & $-5.16(-13.473 .1)$ & 0.21 \\
\hline $\mathrm{NC}-$ vs control & $-7.4(-15.590 .79)$ & 0.07 \\
\hline$\left(\mathrm{NC}+\mathrm{NC}^{-}\right)$vs control & $-6.28(-13.631 .07)$ & 0.09 \\
\hline \multicolumn{3}{|l|}{ Total kidney volume girls } \\
\hline $\mathrm{NC}+$ vs NC- & $7.66(-6.93+22.25)$ & 0.28 \\
\hline $\mathrm{NC}+$ vs control & $-14.76(-29.04-0.49)$ & $0.04 *$ \\
\hline $\mathrm{NC}-$ vs control & $-22.42(-38.76-6.08)$ & $0.009 *$ \\
\hline$\left(\mathrm{NC}+\mathrm{NC}^{-}\right)$vs control & $-18.59(-32.09-5.1)$ & $0.009 *$ \\
\hline \multicolumn{3}{|l|}{ Total kidney volume boys } \\
\hline $\mathrm{NC}+$ vs NC- & $-6.83(-21.88+8.22)$ & 0.36 \\
\hline $\mathrm{NC}+$ vs control & $-6.7(-25.29+11.89)$ & 0.46 \\
\hline $\mathrm{NC}-$ vs control & $0.12(-15.63+15.94)$ & 0.98 \\
\hline$\left(\mathrm{NC}+\mathrm{NC}^{-}\right)$vs control & $-3.28(-18-81+12.24)$ & 0.66 \\
\hline
\end{tabular}

Results from the ANCOVA analysis models and planned comparisons. * $p$ values are regarded as significant $(p$ values $<0.05)$

measurements are capable of reflecting true elevation of blood pressure or if there is a risk for overestimation. When we measured 24-h blood pressure in the preterm-born children, only one of the 5 children with office blood pressure above the 90th percentile had also elevated blood pressure in the ABPM.

The results of the ambulatory blood pressure measurements were within the normal limits for systolic and diastolic age and height related percentiles (<90th) [22]. However, we were very surprised by the high number of "non-dippers" among the children born premature. In 17 out of 34 (50\%) children with reliable 24 -h readings, the blood pressure difference between day and night time was less than what is generally regarded as normal (10\% difference) [39]. The relevance of "non-dippers" has been well described for adults and has been strongly associated with worse cardiovascular outcome and can be interpreted as a marker preceding the development of hypertension and microvascular complications [40, 41]. There is very limited data available for children on night-dipping, but a few studies confirm that the $10 \%$ rule should be valid for children in the age group we investigated [22]. Night dipping seems to be related to age. Varda et al. observed in infants and toddlers from 2 to 30 months old a less pronounced night dip of only 5.4\% on average [42]. A recent study observed a close relationship between non-dippers and BMI with children with primary hypertension and overweight or obesity showing a lack of decline of nocturnal blood pressure values [43]. Unfortunately, that study lacks information on GA or birth weight. We are unable to explain the "non-dipping" phenomena with overweight or obesity in our study as only 4 out of the 17 non-dipper children had a BMI at or over the 90th percentile.

Among the scarce evidence available for preterm-born children, a study in 41 preterm-born children (26-36 weeks GA) examined at the age of 7 years found in comparison with 27 healthy controls insufficient night dipping in $73 \%$ of the preterm group compared with $41 \%$ in the control group [44]. It is rather unclear why the prevalence of non-dipping is so high among healthy control children in this study. Another recent and slightly larger study investigated 78 preterm-born children (27 weeks mean GA) and compared them with 38 healthy 
Table 4 Results for kidney volumes using BSA-related KV (KV/BSA) for the different groups

Estimated difference $\quad p$

(CI 95\%)

Total Kidney volume (KV/BSA)

\begin{tabular}{lll}
$\mathrm{NC}+$ vs NC- & $-4.21(-15.29+6.86)$ & 0.44 \\
$\mathrm{NC}+$ vs control & $-14.02(-25.37-2.66)$ & $0.016^{*}$ \\
$\mathrm{NC}-$ vs control & $-9.8(-20.88+1.27)$ & 0.08 \\
(NC+ NC-) vs control & $-11.8(-21.51-2.09)$ & $0.018^{*}$ \\
Right kidney volume (KV/BSA) & \\
NC+ vs NC- & $-5.04(-11.0+0.93)$ & 0.09 \\
NC+ vs control & $-9.21(-15.33-3.08)$ & $0.003^{*}$ \\
NC- vs control & $-4.16(-10.22+1.89)$ & 0.17 \\
(NC+ NC-) vs control & $-6.62(-12.01-1.23)$ & $0.016^{*}$ \\
Left kidney volume (KV/BSA) & & \\
NC+ vs NC- & $-2.4(-10.9+5.96)$ & 0.55 \\
NC+ vs control & $-6.99(-15.64+1.64)$ & 0.11 \\
NC- vs control & $-9.47(-18.01-0.92)$ & $0.03^{*}$ \\
NC+ NC-) vs control & $-8.26(-15.7-0.82)$ & $0.03^{*}$ \\
\hline
\end{tabular}

Results from the ANCOVA analysis models and planned comparisons. ${ }^{*} p$ values are regarded as significant $(\mathrm{p}$ values $<0.05)$ term control children at the mean age of 6.7 years, but found only $16.7 \%$ versus $5.2 \%$ non-dippers [30]. Hovi et al. investigated 118 young adults (18 to 27 years of age) born with VLBW and could identify $31.2 \%$ "non-dippers" among those, along with the main findings of increased 24-h systolic blood pressure of $2.4 \mathrm{mmHg}$ in young adults born with VLBW [45].

The variation of blood pressure over $24 \mathrm{~h}$ is regulated by the autonomic nervous system (ANS) via the hypothalamopituitary-adrenal axis [46]. It has recently been shown by us and others that the ANS might be altered in children born very premature [47-49]. However, the normal or even relatively low blood pressure during daytime in some of our pretermborn school children might reflect physical inactivity during the day and not allowing further dipping during nighttime. Although we are convinced that these data are of importance, they have to be interpreted with caution and further follow-up on this cohort is needed.

A general weakness of this study is the size, as the numbers in all three groups are limited. We regard it as a strength that we have analyzed KV with different methods and have thoroughly tested adjusting for different variables. Our investigation and analysis allowed us to make clear differentiations for gender as well as for right and left kidney sides. It was also beneficial that all study subjects were recruited from the same hospital which minimized confounding effects by different practices
Fig. 3 Total kidney volume presented as a ratio to body surface area (KV/BSA) for children born extremely preterm (EPT, both $\mathrm{NC}+$ and $\mathrm{NC}^{-}$) and controls. *Significant difference between EPT and controls ( $p$ values $<0.05$ ). Results from the ANCOVA analysis models and planned comparisons

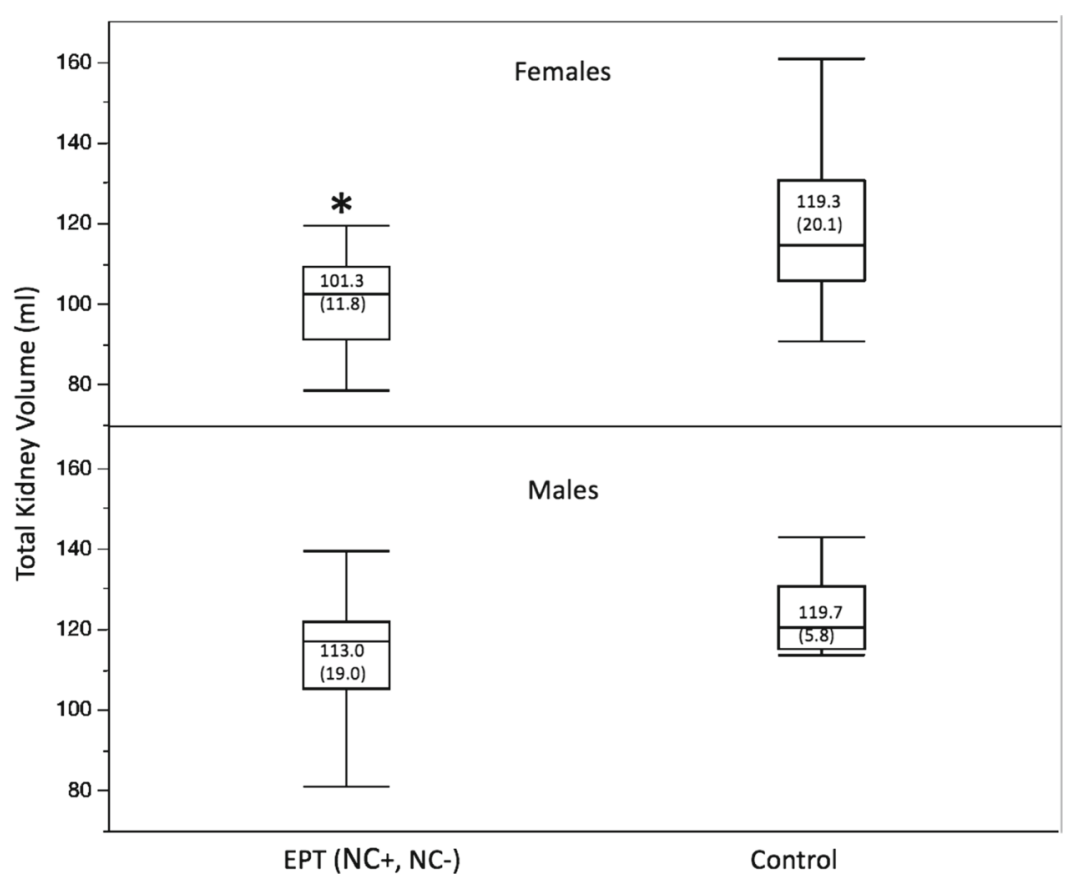

* indicates significant difference between EPT and Controls

( $P$ values $<0.05)$. Results from the ANCOVA analysis models and planned comparisons. 
Table 5 Results for ABPM (presented as numbers for percentiles) for the three groups

\begin{tabular}{llll}
\hline & $\mathrm{NC}+(14)$ & $\mathrm{NC}-(20)$ & $p$ \\
\hline 24-h ABPM systolic percentiles & & & \\
$<$ 50th & 9 & 14 & 0.7 \\
50-75th & 5 & 3 & 0.2 \\
75-90th & 0 & 3 & 0.1 \\
$>$ 90th & 0 & 0 & \\
24-h ABPM diastolic percentiles & & & \\
$<$ 50th & 13 & 17 & 0.5 \\
50-75th & 1 & 2 & 0.7 \\
75-90th & 0 & 1 & 0.4 \\
$>$ 90th & 0 & 0 & \\
Day-to-night decrease $<10 \%$ & & & \\
Patients, $n(\%)$ & $9(64.3 \%)$ & $8(40 \%)$ & 0.16 \\
\hline
\end{tabular}

Differences between NC+ and NC- groups analyzed with Pearson's chisquare test. The normal percentiles are taken from reference [22]

and that all histories and ultrasound examinations were performed by the same investigator, as well as all anthropometric measurements being taken by the same research nurse. ABPM were only taken in the EPT group and thus correlated to population blood pressure references which is another weakness.

\section{Conclusion}

In this study, we showed that children at the age of 6-10 years born EPT have significantly smaller kidney volume and lower cystatin C-based GFR, but within normal limits. Our results do not entirely support our hypothesis that $\mathrm{NC}$ which developed during the neonatal period has a significant impact on reduced kidney volume at school age. However, the NC+ group of EPTborn children had significantly lower renal growth. Kidney function at school age has not been affected by NC. The high number of non-dippers in preterm-born children at school age is a new observation and has potential implications for the development of hypertension. However, the clinical significance of this finding needs to be studied further. It is important to know when early morphological changes such as the reduced nephron endowment lead to clinical findings in children born prematurely. As more EPT infants are surviving, research describing the consequences is essential in order to be prepared for adequate support and to organize early preventive efforts for this high-risk group.

Acknowledgments Special thanks to Gordana Printz, Amanda Rosberg, and Edward Nilsson for recruitment work and data collection. We sincerely thank the participating children and families for making this study possible.

Funding information The study was funded by Sällskapet Barnavård and Karolinska FOUU (Research, Education and Development Funding).
Compliance with ethical standards The study was approved by the Ethical Committee at Karolinska University Hospital. Written and oral consent was obtained from all parents and children.

Conflict of interest The authors declare that they have no conflict of interest.

Open Access This article is distributed under the terms of the Creative Commons Attribution 4.0 International License (http:// creativecommons.org/licenses/by/4.0/), which permits unrestricted use, distribution, and reproduction in any medium, provided you give appropriate credit to the original author(s) and the source, provide a link to the Creative Commons license, and indicate if changes were made.

\section{References}

1. Brenner BM, Garcia DL, Anderson S (1988) Glomeruli and blood pressure. Less of one, more the other? Am J Hypertens 1(4 Pt 1): 335-347

2. Hinchliffe SA, Lynch MR, Sargent PH, Howard CV, Van Velzen D (1992) The effect of intrauterine growth retardation on the development of renal nephrons. Br J Obstet Gynaecol 99:296-301

3. Rodriguez MM, Gomez AH, Abitbol CL, Chandar JJ, Duara S, Zilleruelo GE (2004) Histomorphometric analysis of postnatal glomerulogenesis in extremely preterm infants. Pediatr Dev Pathol 7:17-25. https://doi.org/10.1007/s10024-003-3029-2

4. Abitbol CL, DeFreitas MJ, Strauss J (2016) Assessment of kidney function in preterm infants: lifelong implications. Pediatr Nephrol 31:2213-2222. https://doi.org/10.1007/s00467-016-3320-x

5. Bakker H, Kooijman MN, van der Heijden AJ, Hofman A, Franco OH, Taal HR, Jaddoe VW (2014) Kidney size and function in a multi-ethnic population-based cohort of school-age children. Pediatr Nephrol 29:1589-1598. https://doi.org/10.1007/s00467014-2793-8

6. Bertram JF, Douglas-Denton RN, Diouf B, Hughson MD, Hoy WE (2011) Human nephron number: implications for health and disease. Pediatr Nephrol 26:1529-1533. https://doi.org/10.1007/ s00467-011-1843-8

7. Saarela T, Vaarala A, Lanning P, Koivisto M (1999) Incidence, ultrasonic patterns and resolution of nephrocalcinosis in very low birthweight infants. Acta Paediatr 88:655-660

8. Hoppe B, Duran I, Martin A, Kribs A, Benz-Bohm G, Michalk DV, Roth B (2002) Nephrocalcinosis in preterm infants: a single center experience. Pediatr Nephrol 17:264-268. https://doi.org/10.1007/ s00467-001-0816-8

9. Giapros V, Tsoni C, Challa A, Cholevas V, Argyropoulou M, Papadopoulou F, Siomou E, Drougia A, Andronikou S (2011) Renal function and kidney length in preterm infants with nephrocalcinosis: a longitudinal study. Pediatr Nephrol 26:18731880. https://doi.org/10.1007/s00467-011-1895-9

10. Hufnagle KG, Khan SN, Penn D, Cacciarelli A, Williams P (1982) Renal calcifications: a complication of long-term furosemide therapy in preterm infants. Pediatrics 70:360-363

11. Chang HY, Hsu CH, Tsai JD, Li ST, Hung HY, Kao HA, Chang JH, Chung HY, Wang HK (2011) Renal calcification in very low birth weight infants. Pediatr Neonatol 52:145-149. https://doi.org/10. 1016/j.pedneo.2011.03.004

12. Cranefield DJ, Odd DE, Harding JE, Teele RL (2004) High incidence of nephrocalcinosis in extremely preterm infants treated with dexamethasone. Pediatr Radiol 34:138-142. https://doi.org/10. 1007/s00247-003-1090-7 
13. Lee CC, Chan OW, Lai MY, Hsu KH, Wu TW, Lim WH, Wang YC, Lien R (2017) Incidence and outcomes of acute kidney injury in extremely-low-birth-weight infants. PLoS One 12:e187764. https://doi.org/10.1371/journal.pone.0187764

14. Galu SC, Hascoet JM, Vieux R (2015) Impact of neonatal factors and nutrition on kidney size in 5-year-old preterm-born children. Am J Perinatol 32:219-224. https://doi.org/10.1055/s-00341374816

15. Vierge M, Laborie S, Bertholet-Thomas A, Carlier MC, Picaud JC, Claris O, Bacchetta J (2017) Neonatal intoxication to vitamin D in premature babies: a series of 16 cases. Arch Pediatr 24:817-824. https://doi.org/10.1016/j.arcped.2017.06.016

16. Porter E, McKie A, Beattie TJ, McColl JH, Aladangady N, Watt A, White MP (2006) Neonatal nephrocalcinosis: long term follow up. Arch Dis Child Fetal Neonatal Ed 91:F333-F336. https://doi.org/ 10.1136/adc.2006.094755

17. Kist-van Holthe JE, van Zwieten PH, Schell-Feith EA, Zonderland HM, Holscher HC, Wolterbeek R, Veen S, Frolich M, van der Heijden BJ (2007) Is nephrocalcinosis in preterm neonates harmful for long-term blood pressure and renal function? Pediatrics 119: 468-475. https://doi.org/10.1542/peds.2006-2639

18. Marsal K, Persson PH, Larsen T, Lilja H, Selbing A, Sultan B (1996) Intrauterine growth curves based on ultrasonically estimated foetal weights. Acta Paediatr 85:843-848

19. Du Bois D, Du Bois EF (1989) A formula to estimate the approximate surface area if height and weight be known. 1916. Nutrition 5: 303-311 discussion 312-303

20. Ostchega Y, Hughes JP, Prineas RJ, Zhang G, Nwankwo T, Chiappa MM (2014) Mid-arm circumference and recommended blood pressure cuffs for children and adolescents aged between 3 and 19 years: data from the National Health and Nutrition Examination Survey, 1999-2010. Blood Press Monit 19:26-31. https://doi.org/ $10.1097 / \mathrm{mbp} .0000000000000008$

21. (2004) The fourth report on the diagnosis, evaluation, and treatment of high blood pressure in children and adolescents. Pediatrics 114(2 Suppl 4th Report):555-576

22. Lurbe E, Agabiti-Rosei E, Cruickshank JK, Dominiczak A, Erdine S, Hirth A, Invitti C, Litwin M, Mancia G, Pall D, Rascher W, Redon J, Schaefer F, Seeman T, Sinha M, Stabouli S, Webb NJ, Wuhl E, Zanchetti A (2016) 2016 European Society of Hypertension guidelines for the management of high blood pressure in children and adolescents. J Hypertens 34:1887-1920. https://doi. org/10.1097/hjh.0000000000001039

23. Grubb A, Horio M, Hansson LO, Bjork J, Nyman U, Flodin M, Larsson A, Bokenkamp A, Yasuda Y, Blufpand H, Lindstrom V, Zegers I, Althaus H, Blirup-Jensen S, Itoh Y, Sjostrom P, Nordin G, Christensson A, Klima H, Sunde K, Hjort-Christensen P, Armbruster D, Ferrero C (2014) Generation of a new cystatin Cbased estimating equation for glomerular filtration rate by use of 7 assays standardized to the international calibrator. Clin Chem 60: 974-986. https://doi.org/10.1373/clinchem.2013.220707

24. Schwartz GJ, Haycock GB, Edelmann CM Jr, Spitzer A (1976) A simple estimate of glomerular filtration rate in children derived from body length and plasma creatinine. Pediatrics 58:259-263

25. Dinkel E, Ertel M, Dittrich M, Peters H, Berres M, SchulteWissermann H (1985) Kidney size in childhood. Sonographical growth charts for kidney length and volume. Pediatr Radiol 15: $38-43$

26. Scholbach T, Weitzel D (2012) Body-surface-area related renal volume: a common normal range from birth to adulthood. Scientifica 2012:949164. https://doi.org/10.6064/2012/949164

27. Kandasamy Y, Rudd D, Smith R, Lumbers ER, Wright IM (2018) Extra uterine development of preterm kidneys. Pediatr Nephrol. https://doi.org/10.1007/s00467-018-3899-1

28. Abitbol CL, Seeherunvong W, Galarza MG, Katsoufis C, Francoeur D, Defreitas M, Edwards-Richards A, Master Sankar
Raj V, Chandar J, Duara S, Yasin S, Zilleruelo G (2014) Neonatal kidney size and function in preterm infants: what is a true estimate of glomerular filtration rate? J Pediatr 164:1026-1031.e1022. https://doi.org/10.1016/j.jpeds.2014.01.044

29. Rakow A, Johansson S, Legnevall L, Sevastik R, Celsi G, Norman M, Vanpee M (2008) Renal volume and function in school-age children born preterm or small for gestational age. Pediatr Nephrol 23:1309-1315. https://doi.org/10.1007/s00467-008-0824$\mathrm{z}$

30. Kwinta P, Klimek M, Drozdz D, Grudzien A, Jagla M, Zasada M, Pietrzyk JJ (2011) Assessment of long-term renal complications in extremely low birth weight children. Pediatr Nephrol 26:10951103. https://doi.org/10.1007/s00467-011-1840-y

31. Starzec K, Klimek M, Grudzien A, Jagla M, Kwinta P (2016) Longitudinal assessment of renal size and function in extremely low birth weight children at 7 and 11 years of age. Pediatr Nephrol 31:2119-2126. https://doi.org/10.1007/s00467-016-34136

32. Koike K, Ikezumi Y, Tsuboi N, Kanzaki G, Haruhara K, Okabayashi Y, Sasaki T, Ogura M, Saitoh A, Yokoo T (2017) Glomerular density and volume in renal biopsy specimens of children with proteinuria relative to preterm birth and gestational age. Clin J Am Soc Nephrol 12:585-590. https://doi.org/10.2215/cjn. 05650516

33. Brenner BM, Chertow GM (1994) Congenital oligonephropathy and the etiology of adult hypertension and progressive renal injury. Am J Kidney Dis 23:171-175

34. Keijzer-Veen MG, Devos AS, Meradji M, Dekker FW, Nauta J, van der Heijden BJ (2010) Reduced renal length and volume 20 years after very preterm birth. Pediatr Nephrol 25:499-507. https://doi. org/10.1007/s00467-009-1371-y

35. Berg UB, Nyman U, Back R, Hansson M, Monemi KA, Herthelius M, Bjork J (2015) New standardized cystatin C and creatinine GFR equations in children validated with inulin clearance. Pediatr Nephrol 30:1317-1326. https://doi.org/10.1007/s00467-015-30603

36. Levey AS, Eckardt KU, Tsukamoto Y, Levin A, Coresh J, Rossert J, De Zeeuw D, Hostetter TH, Lameire N, Eknoyan G (2005) Definition and classification of chronic kidney disease: a position statement from Kidney Disease: Improving Global Outcomes (KDIGO). Kidney Int 67:2089-2100. https://doi.org/10.1111/j. 1523-1755.2005.00365.x

37. Bonamy AK, Kallen K, Norman M (2012) High blood pressure in 2.5-year-old children born extremely preterm. Pediatrics 129 : e1199-e1204. https://doi.org/10.1542/peds.2011-3177

38. Vashishta N, Surapaneni V, Chawla S, Kapur G, Natarajan G (2017) Association among prematurity ( $<30$ weeks' gestational age), blood pressure, urinary albumin, calcium, and phosphate in early childhood. Pediatr Nephrol 32:1243-1250. https://doi.org/10.1007/ s00467-017-3581-z

39. Asayama K, Satoh M, Kikuya M (2018) Diurnal blood pressure changes. Hypertens Res. https://doi.org/10.1038/s41440-0180054-0

40. Satoh M, Asayama K, Kikuya M, Inoue R, Tsubota-Utsugi M, Obara T, Murakami K, Matsuda A, Murakami T, Nomura K, Metoki H, Imai Y, Ohkubo T (2018) Nocturnal blood pressure decline based on different time intervals and long-term cardiovascular risk: the Ohasama Study. Clin Exp Hypertens 40:1-7. https:// doi.org/10.1080/10641963.2016.1259324

41. Mateo-Gavira I, Vilchez-Lopez FJ, Garcia-Palacios MV, Carral-San Laureano F, Jimenez-Carmona S, Aguilar-Diosdado M (2016) Nocturnal blood pressure is associated with the progression of microvascular complications and hypertension in patients with type 1 diabetes mellitus. J Diabetes Complicat 30:1326-1332. https://doi. org/10.1016/j.jdiacomp.2016.05.021 
42. Varda NM, Gregoric A (2005) Twenty-four-hour ambulatory blood pressure monitoring in infants and toddlers. Pediatr Nephrol 20: 798-802. https://doi.org/10.1007/s00467-005-1857-1

43. Jedzura A, Adamczyk P, Bjanid O, Swietochowska E, Roszkowska-Bjanid D, Baraniecka A, Banaszak B, Plesinski K, Morawiec-Knysak A, Ziora K, Szczepanska M (2017) Nondipping status and selected adipokines concentration in children with primary arterial hypertension. Clin Exp Hypertens 39:718725. https://doi.org/10.1080/10641963.2017.1324474

44. Bayrakci US, Schaefer F, Duzova A, Yigit S, Bakkaloglu A (2007) Abnormal circadian blood pressure regulation in children born preterm. J Pediatr 151:399-403. https://doi.org/10.1016/j.jpeds.2007. 04.003

45. Hovi P, Andersson S, Raikkonen K, Strang-Karlsson S, Jarvenpaa AL, Eriksson JG, Pesonen AK, Heinonen K, Pyhala R, Kajantie E (2010) Ambulatory blood pressure in young adults with very low birth weight. J Pediatr 156:54-59.e51. https://doi.org/10.1016/j. jpeds.2009.07.022

46. Imai Y, Abe K, Sasaki S, Minami N, Munakata M, Nihei M, Sekino H, Yoshinaga K (1989) Exogenous glucocorticoid eliminates or reverses circadian blood pressure variations. J Hypertens 7:113120
47. Rakow A, Katz-Salamon M, Ericson M, Edner A, Vanpee M (2013) Decreased heart rate variability in children born with low birth weight. Pediatr Res 74:339-343. https://doi.org/10.1038/pr.2013. 97

48. Souza LV, Oliveira V, De Meneck F, Grotti Clemente AP, Strufaldi MW, Franco MD (2017) Birth weight and its relationship with the cardiac autonomic balance in healthy children. PLoS One 12: e0167328. https://doi.org/10.1371/journal.pone.0167328

49. Johansson S, Norman M, Legnevall L, Dalmaz Y, Lagercrantz H, Vanpee M (2007) Increased catecholamines and heart rate in children with low birth weight: perinatal contributions to sympathoadrenal overactivity. J Intern Med 261:480-487. https:// doi.org/10.1111/j.1365-2796.2007.01776.x

Publisher's note Springer Nature remains neutral with regard to jurisdictional claims in published maps and institutional affiliations. 